\title{
The Integration Study of High Binding Concrete Energy Storage Piles
}

\author{
Liguang Xiao ${ }^{1, a}$, Dawei Jiang ${ }^{1, b}$ \\ ${ }^{1}$ School of Materials Science and Engineering, Jilin Jianzhu university, Changchun 130118, China \\ axlg627@163.com, ${ }^{b} 775008831 @ q q . c o m$
}

Keywords: Energy storage piles; Mechanical property; Heat transfer failure; Interfacial transition zone; The integration study.

Abstract. This paper was directed to solve the energy-saving and environmental protection technology. Solved the practical problem of the significant reduce of mechanical property when we putted the heat transfer pipes into the concrete pile, and solved the problem of the thin air layer between the concrete and the heat transfer pipes when the energy storage piles after a long working hours. Discussion and analysis the law of the mechanical property changes of the concrete pile. Proposed and demonstrated the new research methods of energy storage piles "Integration of energy storage pile".

\section{Introduction}

Due to the sharp decrease of non-renewable energy reserves of global, Sustainable development has grew up as a focus problem of all mankind must to face. Take China, More than $30 \%$ of the total energy consumption was consumed by the buildings, And more than $50 \%$ of building energy consumption was consumed by heating and air conditioning which was waste coal resources as the main source, Thus, the pile buried pipe of ground source heat pump technology, As a new kind of building energy efficiency technology, It has been paid much attention by more construction workers. It has been completed the design from the separate construction to the more economical and efficient direct construction, But there was still a series of problems need us to solve $\mathrm{e}^{[1-3]}$. Such as: When the energy storage piles was heating or cooling, the axial compressive stress value will be became $50 \%$ to $100 \%$ of the theoretical value ${ }^{[4]}$; And it would be serious impact strength of the pile after we putted the heat transfer tubes into it, and it will be more impact when we putted more into it ${ }^{[5]}$. Therefore, this paper was focuses on analysis the reason for the changes of mechanical properties of the concrete energy storage piles after the heat transfer tubes putted into it, and it will make recommendations for the material selection and preparation process of the pile with the integration study, so that it can provide the foundation to solve the problem of the lack of mechanical property and thermal property.

\section{The analysis of energy storage pile integration study}

Related articles show, There was no precedent study about the heat transfer pipes and the concrete pile used the integration study method. The existing research was still given priority to with simple concrete research, Even by the method of addition the super plasticizer ,reinforcing fibers and other methods into the concrete to make the pile strength increased ${ }^{[6]}$, But the energy storage pile still first cracked around the heat transfer tubes when we pressure it, and there was still a serious problem of heat exchanger failure after we used the energy storage piles for a long time, because of the thin air layer which appeared between the pile and the heat transfer tube ${ }^{[5]}$. So the integration study will provide a new, integrated and efficient way for this energy saving technology.

The so-called "The integration study " was the method which was make the concrete and the pile as a whole for study and design, Through the way of collaborative design complete the design of material and the heat transfer tubes, Eventually make the transfer pipe and concrete as a whole, Thus effectively improving the mechanical properties, and it will be solve the problem of the thin air layer between the concrete and the heat transfer pipes when the energy storage piles after long working hours. The concept of integration study shown in figure 1 and figure 2: 


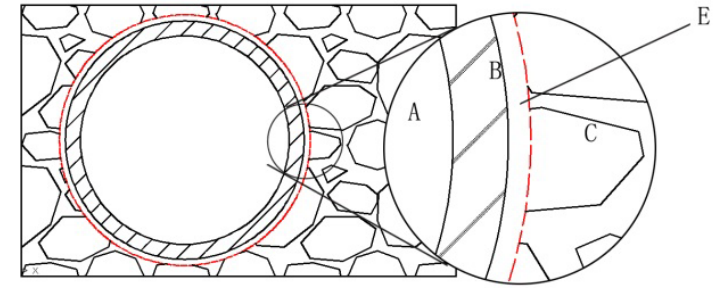

Fig .1. Surface of original design method

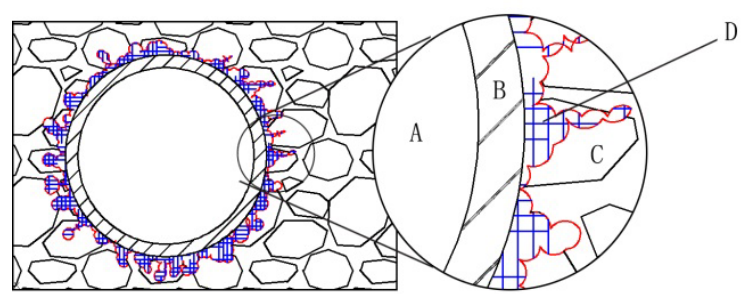

Fig .2. Surface of the integrated design method

In figure 1 and t figure 2, A said the internal heat transfer tube; B said the heat transfer tube; $C$ said the concrete; D said the concrete surface of the integrated design method; E said the concrete surface of original design method. By figure 2, After used integrated design, What we want to achieve effect was to reduce great extent, or completely solve the negative consequences of the junction interface transition layer of original concrete, and ensure it was not produce a thin air layer between the concrete and the heat transfer pipes when the energy storage piles after long working hours, to ensure the pile intensity and the heat transfer performance of the energy storage piles.

\section{The experimental process}

Selection of raw materials and Concrete mix proportion. The strength grade of 42.5 of General Portland cement of Dinglu brand; the sand with fineness modulus of 2.4; the continuous gradation of basalt rock with $D_{\max }=20 \mathrm{~mm}$; the pipe of PP-R with diameter for $20 \mathrm{~mm}$; The self-made vinyl acetate/butyl acrylate/acrylic acid/acrylonitrile four component without soap vinegar acrylic emulsion; drinking water. The concrete mix proportion: the water-binder ratio of w/c $=0.6$, The design strength for C30, One cubic meter concrete contain with350.0 Kg cement, and $668.0 \mathrm{Kg}$ sand, and $1137.0 \mathrm{Kg}$ gravel.

Sample production and maintenance. The experimental mix proportion was shown in the table 1. The group 1, group 2 and group 3 have the same water- binder ratio, and the group 1 was not added heat transfer tubes, and the group 2 was added the heat transfer tubes which was not used the integrated treatment methods, and group 3 was added the heat transfer tubes which had used the integrated treatment methods; the group 4 and the group 5 was the comparison test of the group 2, and the water-cement ratio of the group 4 was $w / c=0.65$, and the water-cement ratio of the group 5 was $\mathrm{w} / \mathrm{c}=0.55$.

Tab.1. The experimental mix

\begin{tabular}{cccccccc}
\hline group & W/C & cement (Kg) & water $(\mathrm{Kg})$ & sand $(\mathrm{Kg})$ & rock $(\mathrm{Kg})$ & Heat transfer tubes & the heat transfer tubes surface \\
\hline 1 & 0.6 & 1.225 & 0.735 & 2.34 & 4.105 & no add & no disposition \\
2 & 0.6 & 1.225 & 0.735 & 2.34 & 4.105 & add & no disposition \\
3 & 0.6 & 1.225 & 0.735 & 2.34 & 4.105 & add & disposition \\
4 & 0.65 & 1.225 & 0.795 & 2.34 & 4.105 & add & no disposition \\
5 & 0.55 & 1.225 & 0.647 & 2.34 & 4.105 & add & no disposition
\end{tabular}

First, according to the experimental test mode size cutting the heat transfer tubes, As shown in figure 3-4, the heat transfer tubes each have100 mm long, Produced 12 segments of the heat transfer tubes, and divided them into four groups, And disposition the fourth group of heat transfer tube surface with the integrated study, and we should disposition the fourth group of heat transfer tube surface with the four component without soap vinegar acrylic emulsion before the experiment;

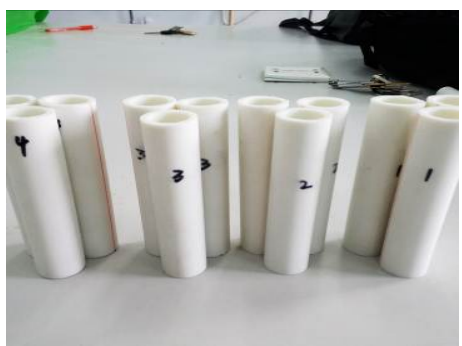

Fig .3. Heat transfer tubes

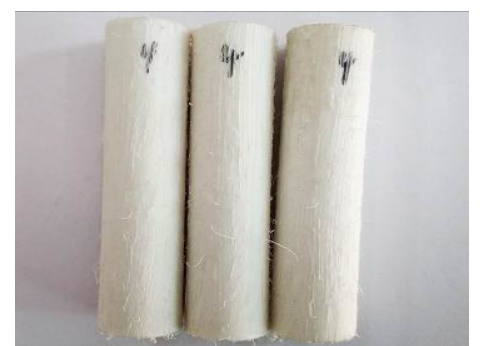

Fig .4. Surface has processed 
According to the "standard of ordinary concrete mechanical properties experimental method" start experiment, In order to ensure the heat transfer tubes in the central part of the test pieces, we should pasted the location bar on the inner surface of the mold . Released and numbered after 24 hours, Put it into the standard constant temperature and humidity curing box curing for 28 days, and then take it out for the test.

\section{The experimental results and analysis}

Blocks compressive strength results were shown in table 2.

Tab.2.The compressive strength experiment results

\begin{tabular}{c|c|c|c|c|c}
\hline group & block1 $(\mathrm{KN})$ & block2 $(\mathrm{KN})$ & block 3 $(\mathrm{KN})$ & average $(\mathrm{KN})$ & compressive strength $(\mathrm{MP})$ \\
\hline 1 & 310.15 & 307.34 & 296.85 & 304.78 & 28.95 \\
\hline 2 & 267.57 & 270.71 & 253.08 & 263.79 & 25.06 \\
\hline 3 & 285.39 & 278.89 & 277.95 & 280.74 & 26.67 \\
\hline 4 & 222.10 & 227.21 & 220.44 & 223.25 & 21.20 \\
\hline 5 & 335.54 & 329.55 & 309.33 & 324.80 & 30.80 \\
\hline
\end{tabular}

According to the group 1, group 2 and group 3 compressive strength, drew a line chart of compressive strength (as shown in Fig.5), At the same time, according to the table1 and compared with the group 1 and the group 2 compressive strength value, we could find that the concrete block compressive strength was decreased obviously, and only $86.5 \%$ compressive strength had achieved after heat transfer tube put into it, Compared with group 1 and group 3 resistance strength, we could find after we used the integration study methods, the compressive strength of group3 has been achieved 92.1\% compressive strength of the group 1, it has improved $6.4 \%$ compressive strength than the group 2, can be seen by the method of integration, to join the heat exchange tube of block strength has greatly improved. We could obviously find the compressive strength had been improved after we used the integration study methods.

According to the group 2, group 4 and the group 5 compressive strength value of the experiment, drew the line chart of the different water-binder ratio experimental block compressive strength (as shown in Fig.6), Compared the compressive strength value of this three groups of experiments, we could effectively increase the compressive strength by the way of low water-binder ratio after we added the heat exchange tube into the energy storage piles
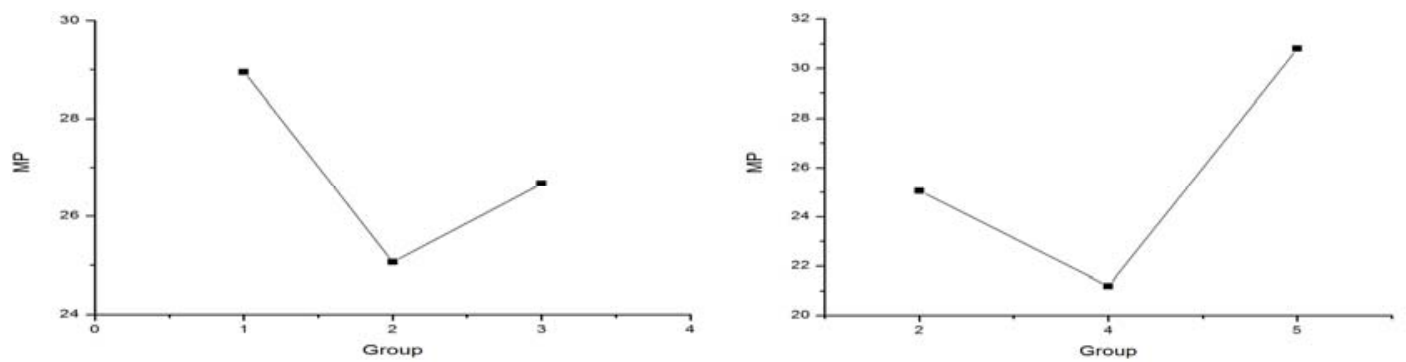

Fig .5. Group 1, 2, 3 compressive strength line chart Fig .6. Group 2, 4, 5 compressive strength line chart

The destruction of the group 1, 2 and 3 as shown in figure 7-9, It could be found in the experiment that the group 2 was damaged greater than the group 1; and it could be found that first damage begins around the heat transfer tube of group 2, and through the figure 9, it could be found that the end face of block did not occur damage after we used the integrated study method; And it could be seen the bonding interface between the concrete and the heat transfer tubes was very smooth, and the bonding interface was very rough after we used the integration study methods. Through the above experimental results, it could better inhibit the damage by the integration study methods, and it would be appeared a good interfacial transition zone between the concrete and the transfer tubes. 


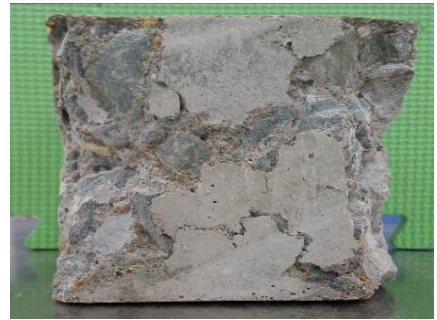

Fig .7. Destruction of the group1 group3

The figure 10 to 11 was the magnified 3000 times micrograph of the group 2 and group 3 by scanning electron microscope, The prominently ribbed body was the damage surface which was not used the integration study methods in the lift of the figure 10; By compared figures it could be found which used the integration study methods had an obvious transition layer interface as shown and there was a close combination between the cement and polymer emulsion ,and there was not have obvious boundary transition zone.

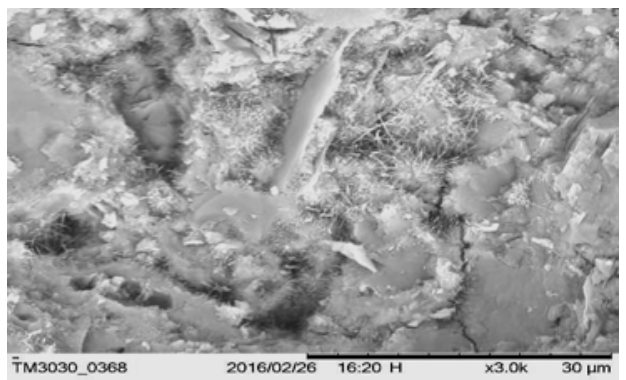

Fig .10. Normal block TMEx3000

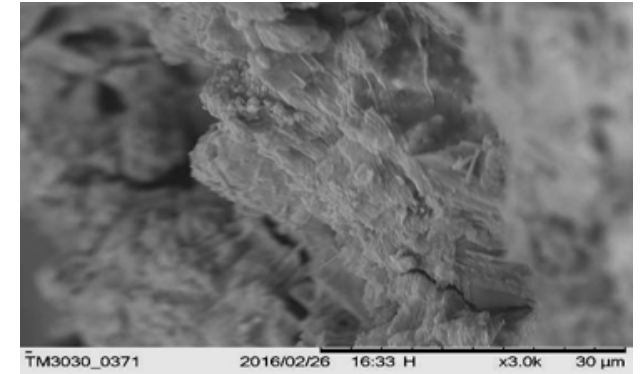

Fig .11. Integrated block TMEx3000

When we saw the transfer tube as a coarse rock which has a very low absorption of water on the microstructure analysis, In this case it could be analysis by boundary transition of concrete science, and explanation the reason why the compressive strength will be reduce and there will be appear a thin air layer between the concrete and the heat transfer pipes when the energy storage piles after long working hours. Because the construction of energy storage piles requires to minimize vibration effects on heat transfer tube, So during the construction of concrete, we always try to increase the water-cement ratio or added concrete super plasticizer to achieve a higher degree of fluidity, So there would be generated a large number of $\mathrm{Ca}(\mathrm{OH})_{2}$ which orientation growth and larger particles ettringite crystals, Greatly reducing the overall of energy storage pile, and greatly reduced the mechanical property. At the same time this weaker binding led to the thin air layer appear between the concrete and the heat transfer pipes when the energy storage piles after long working hours, and eventually led the heat transfer failure.

\section{Conclusions}

In summary, from the mechanics point of view, after the integration study methods, the synergy of the heat transfer tubes and concrete have been improved; from the boundary transition theoretical analysis, after integration study methods, reduced the highly destructive interface transition, and increased the interface layer density between concrete and the heat transfer tubes, Thereby it was increased the resist damage ability of the blocks.

\section{References}

[1] Rui Fan, Zuiliang Ma:Review and improvement on heat transfermodel of ground heat exchangers. Heating Ventilating \& Air Conditioning 2006，36(4),p.25-29 ( In Chinese )

[2] Gerald W.Huttrer, Geothermal heat pumps:an increasingly successful technology . Renewable Energy Vol.10(1997),p.481-488 
[3] William S Fleming:Ground source heat pump design and operation-Experience within an Asian Country.ASHRAE Transactions Part2(1998),p.771-774

[4] B. L. Amatya, K. Soga, P. J. Boume-webb, T. Amis, L. Laloui:Thermo-mechanical behaviour of energy piles. Geotechnique 2012,p.503-519

[5] Songying Zhao:thermal test and numberical simulation research on energy storage pile.Jilin University 2015 (In Chinese)

[6] Songying Zhao,Dawei Jiang,Xiaodong Song:The R esearch on Materials Selection About Heat Accumulation Technology of Energy pile.Journal of Jilin Institute of Architecture \& Civil Engineering 2013 (12),p.32-35（ In Chinese） 